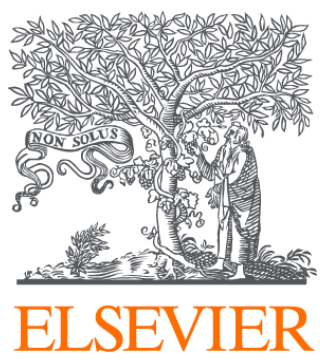

Since January 2020 Elsevier has created a COVID-19 resource centre with free information in English and Mandarin on the novel coronavirus COVID-

19. The COVID-19 resource centre is hosted on Elsevier Connect, the company's public news and information website.

Elsevier hereby grants permission to make all its COVID-19-related research that is available on the COVID-19 resource centre - including this research content - immediately available in PubMed Central and other publicly funded repositories, such as the WHO COVID database with rights for unrestricted research re-use and analyses in any form or by any means with acknowledgement of the original source. These permissions are granted for free by Elsevier for as long as the COVID-19 resource centre remains active. 


\title{
Use of Tracheostomy During the COVID-19 Pandemic
}

\section{American College of Chest Physicians/American Association for Bronchology and Interventional Pulmonology/Association of Interventional Pulmonology Program Directors Expert Panel Report}

\author{
Carla R. Lamb, MD, FCCP; Neeraj R. Desai, MD, FCCP; Luis Angel, MD, FCCP; Udit Chaddha, MD; \\ Ashutosh Sachdeva, MBBS, FCCP; Sonali Sethi, MD, FCCP; Hassan Bencheqroun, MD, FCCP; Hiren Mehta, MD, FCCP; \\ Jason Akulian, MD, MPH, FCCP; A. Christine Argento, MD, FCCP; Javier Diaz-Mendoza, MD, FCCP; \\ Ali Musani, MD, FCCP; and Septimiu Murgu, MD, FCCP
}

BACKGROUND: The role of tracheostomy during the coronavirus disease 2019 (COVID-19) pandemic remains unknown. The goal of this consensus statement is to examine the current evidence for performing tracheostomy in patients with respiratory failure from COVID-19 and offer guidance to physicians on the preparation, timing, and technique while minimizing the risk of infection to health care workers (HCWs).

METHODS: A panel including intensivists and interventional pulmonologists from three professional societies representing 13 institutions with experience in managing patients with COVID-19 across a spectrum of health-care environments developed key clinical questions addressing specific topics on tracheostomy in COVID-19. A systematic review of the literature and an established modified Delphi consensus methodology were applied to provide a reliable evidence-based consensus statement and expert panel report.

RESULTS: Eight key questions, corresponding to 14 decision points, were rated by the panel. The results were aggregated, resulting in eight main recommendations and five additional remarks intended to guide health-care providers in the decision-making process pertinent to tracheostomy in patients with COVID-19-related respiratory failure.

CONCLUSION: This panel suggests performing tracheostomy in patients expected to require prolonged mechanical ventilation. A specific timing of tracheostomy cannot be recommended. There is no evidence for routine repeat reverse transcription polymerase chain reaction testing in patients with confirmed COVID-19 evaluated for tracheostomy. To reduce the risk of infection in HCWs, we recommend performing the procedure using techniques that minimize aerosolization while wearing enhanced personal protective equipment. The recommendations presented in this statement may change as more experience is gained during this pandemic.

CHEST 2020; 158(4):1499-1514

KEY WORDS: aerosol generating procedure; COVID-19; open surgical tracheostomy; percutaneous dilatational tracheostomy; SARS-CoV-2; tracheostomy

ABBREVIATIONS: AGP = aerosol generating procedure; $\mathrm{CDC}=$ Centers for Disease Control and Prevention; CHEST = American College of Chest Physicians; COVID-19 = coronavirus disease 2019; ETT = endotracheal tube; HCW = health-care worker; HEPA = high-efficiency particulate air; $\mathrm{NP}=$ negative pressure; OST $=$ open surgical tracheostomy; PDT $=$ percutaneous dilatational tracheostomy; $\mathrm{PPE}=$ personal protective equipment;
RT-PCR = reverse transcription polymerase chain reaction; SARS = severe acute respiratory syndrome; SARS-CoV-2 = severe acute respiratory syndrome coronavirus 2019; VAP = ventilator-associated pneumonia

AfFiliations: From the Department of Medicine (Dr Lamb), Division of Pulmonary and Critical Care, Lahey Hospital and Medical 


\section{Summary of Recommendations}

1. We suggest that tracheostomy be considered in coronavirus disease 2019 (COVID-19) patients when prolonged mechanical ventilation is anticipated

(Strong Consensus).

2. There is insufficient evidence for recommending a specific timing for tracheostomy in COVID-19 related respiratory failure (Consensus).

3. We suggest that in patients with COVID-19 related respiratory failure, either open surgical tracheostomy (OST) or percutaneous dilatational tracheostomy (PDT) can be performed in patients expected to require prolonged mechanical ventilation (Strong Consensus).

Remarks: Utilization of techniques which minimize aerosolization is recommended when performing tracheostomy (Strong Consensus).

4. We recommend that enhanced personal protective equipment (PPE) be used to mitigate the risk of health

Center, Burlington, MA; the Chicago Chest Center (Dr Desai), AMITA Health, Lisle, IL; the Department of Medicine (Dr Desai), Division of Pulmonary, Critical Care, Sleep and Allergy, University of Illinois at Chicago, Chicago, IL; the Department of Medicine (Dr Angel), Division of Pulmonary and Critical Care, New York University Langone Health, New York, NY; the Division of Pulmonary, Critical Care and Sleep Medicine (Dr Chaddha), Icahn School of Medicine at Mount Sinai, New York, NY; the Department of Medicine (Dr Sachdeva), Division of Pulmonary and Critical Care, University of Maryland School of Medicine, Baltimore, MD; the Respiratory Institute ( $\mathrm{Dr}$ Sethi), Division of Pulmonary and Critical Care, Cleveland Clinic, Cleveland, OH; the Department of Medicine (Dr Bencheqroun), Division of Pulmonary and Critical Care, University of California Riverside, CA; the Division of Pulmonary and Critical Care and Sleep Medicine (Dr Mehta), University of Florida, Gainesville, FL; the Division of Pulmonary and Critical Care (Dr Akulian), UNC Lineberger Comprehensive Cancer Center, University of North Carolina at Chapel Hill, NC; the Department of Medicine (Dr Argento), Division of Pulmonary and Critical Care, Northwestern University, Feinberg School of Medicine Chicago, IL; the Division of Pulmonary and Critical Care (Dr Diaz-Mendoza), Henry Ford Hospital and Department of Medicine, Wayne State University, Detroit, MI; the Division of Pulmonary Sciences and Critical Care Medicine (Dr Musani), University of Colorado, Denver, CO; and the Division of Pulmonary and Critical Care Medicine (Dr Murgu), The University of Chicago, Chicago, IL.

Drs Lamb and Desai contributed equally to this manuscript.

DISCLAIMER: CHEST Guidelines are intended for general information only, are not medical advice, and do not replace professional medical care and physician advice, which should always be sought for any medical condition. The complete disclaimer for this guideline can be accessed at: http://www.chestnet.org/Guidelines-and-Resources.

CORRESPONDENCE TO: Septimiu Murgu, MD, FCCP, Department of Pulmonary \& Critical Care, University of Chicago Medical Center, 5841 S Maryland Ave, Chicago, IL 60637; e-mail: smurgu@medicine. bsd.uchicago.edu

Copyright (C) 2020 Published by Elsevier Inc under license from the American College of Chest Physicians.

DOI: https://doi.org/10.1016/j.chest.2020.05.571 care worker $(\mathrm{HCW})$ related infection during tracheostomy (Strong Consensus).

Remarks: Tracheostomy is an aerosol generating procedure (AGP) and poses an infection risk to HCW involved in the procedure (Strong Consensus).

\section{We suggest that in patients with COVID-19 related} respiratory failure, tracheostomy is performed in a negative-pressure room, preferably in the ICU. As an alternative, a negative-pressure room in the OR could be used, with special attention to minimizing transportationrelated risk of exposure (Strong Consensus).

Remarks: If negative pressure rooms are unavailable, the procedure could be performed in a normal pressure room equipped with HEPA filters in the presence of a strict door policy (Strong Consensus).

6. We do not recommend routine RT-PCR testing (nasopharyngeal swab or lower respiratory sample) prior to performing tracheostomy in patients with confirmed COVID-19 related respiratory failure (Strong Consensus).

Remarks: There is insufficient evidence to recommend RT-PCR testing in patients with non-COVID-19 respiratory failure prior to tracheostomy. If such testing is performed, we suggest that a lower respiratory sample (endotracheal aspirate) rather than a nasopharyngeal swab be obtained (Consensus).

\section{We recommend that in patients with COVID-19} related respiratory failure, tracheostomy is performed by a team consisting of the least number of providers with the highest level of experience (Strong Consensus).

Remarks: We suggest that prior to the initiation of tracheostomy, a multidisciplinary group of providers including the primary critical care team, palliative care, infectious disease, the procedural and airway team utilize respective expertise to determine the goals of care, patient selection, procedural considerations, as well as workflow to optimize safety of both patient and HCW (Strong Consensus).

8. We suggest that patients be maintained with a closed circuit while on mechanical ventilation with a tracheostomy tube and with in-line suction (Strong Consensus).

\section{Background}

In the current viral pandemic, critically ill patients with COVID-19 account for approximately 5\% of all cases and are responsible for one-quarter of all 
hospitalizations. ${ }^{1,2}$ It appears that most critically ill patients require mechanical ventilation..$^{2-5}$ Because of the acute respiratory failure often requiring deep sedation and neuromuscular blockers, these patients may need prolonged mechanical ventilation and may benefit from a tracheostomy. Tracheostomy data from prior respiratory viral outbreaks are sparse, and the available literature from the current outbreak is very limited. ${ }^{6,7}$ The decision to proceed with tracheostomy in patients with COVID-19 must be patient-centric while protecting the safety of health care workers (HCWs).

Tracheostomy is considered an aerosol generating procedure (AGP), and based on the 2003 severe acute respiratory syndrome (SARS) outbreak, it appears to pose the risk of infection to HCWs. Some experts recommend delaying tracheostomy for at least 2 to 3 weeks in patients with COVID-19-associated respiratory failure. ${ }^{8,9}$ Physicians must determine the role of tracheostomy in patients with COVID-19, which may depend on the predicted clinical course. In some heavily affected areas, the COVID-19 pandemic is impacting health-care systems in an unprecedented manner. Tracheostomy may allow faster liberation from mechanical ventilation, may allow shorter ICU stay, ${ }^{10-13}$ and may impact availability of ICU resources. There are unanswered questions regarding staff preparation and protection, timing, location, technique, and postintervention care for this procedure.

This consensus statement was created to address the knowledge gap. The expert panel represented the American College of Chest Physicians (CHEST), the American Association for Bronchology and Interventional Pulmonology, and the Association of Interventional Pulmonology Program Directors. Eight
TABLE 1 ] Key Questions Pertinent to Tracheostomy During the COVID-19 Pandemic

In patients with COVID-19-related respiratory failure, should tracheostomy be offered to patients expected to require prolonged mechanical ventilation?

In patients with COVID-19-related respiratory failure, should tracheostomy be performed early (within 7-10 d) or late (after 14-21 d)?

In patients with COVID-19-related respiratory failure, should open or percutaneous dilatational tracheostomy be performed?

In patients with COVID-19-related respiratory failure, does the use of PPE mitigate the tracheostomy-related risk of infection to HCWs?

In patients with COVID-19-related respiratory failure, should tracheostomy be performed in the operating room or in the ICU room?

In patients with COVID-19-related respiratory failure, should PCR testing be performed prior to tracheostomy?

In patients with COVID-19-related respiratory failure, should tracheostomy be performed by a multidisciplinary team or a single specialty?

In patients with COVID-19-related respiratory failure who underwent tracheostomy, should standard posttracheostomy care be performed?

COVID-19 = coronavirus disease 2019; HCW = health-care worker; PCR = polymerase chain reaction; PPE $=$ personal protective equipment.

key questions, corresponding to 14 decision points, were rated by the panel (Table 1). The results were aggregated, resulting in eight main recommendations and five additional remarks intended to guide healthcare providers in the decision-making process pertinent to tracheostomy in patients with COVID-19. The statement focuses on selected important issues relating to performing a tracheostomy in critically ill patients with COVID-19 requiring mechanical ventilation.

\section{Methods}

\section{Literature Search}

A comprehensive literature search of MEDLINE (PubMed interface) was executed. The search strategy included both controlled vocabulary, such as the National Library of Medicine's Medical Subject Headings and key words using "tracheostomy" OR "percutaneous tracheostomy" OR "percutaneous dilatational tracheostomy" OR "PEG" OR "percutaneous epigastric tube" AND "coronavirus" OR "coronavirus 2019" OR "COVID19" OR "2019-nCoV" OR "SARS-CoV-2" OR "SARS” OR "MERS” OR "COVID" OR "SARS-CoV" OR "nCoV" between 2000 and the present time (ie, April 15, 2020). Additional Medical Subject Heading searches were performed by using the words "tracheostomy" OR "percutaneous tracheostomy" OR "percutaneous dilation tracheostomy" AND "ultrasound," and "Reverse Transcription Polymerase Chain Reaction," "PCR testing," and "viral shedding" with no language or time restrictions.

Each article was assessed for relevance to the primary objective, and useful references and similar articles were retrieved. No language restrictions were applied. The title, abstract, and full text of all articles captured with these search criteria were assessed, and those reporting the tracheostomy and techniques in patients with and without SARS COVID-19 were included. The reference list of all identified studies was also analyzed to detect additional articles. The typical guideline methodology was not used for this expert panel report. This paper is not a systematic review of the literature using PICO (Patient, Problem or Population, Intervention, Comparison control or comparator) questions, PRISMA (Preferred Reporting Items for Systematic Reviews and Meta-Analyses) diagrams, and tables of evidence.

\section{Consensus Methodology}

Written from multi-institutional and multisociety perspectives, this statement is intended to provide context for the use of tracheostomy 
Reccomendations and Remarks

\begin{tabular}{|c|c|c|c|c|c|c|}
\hline $\begin{array}{l}\text { Recommendation } \\
1\end{array}$ & $\begin{array}{l}\text { We suggest that tracheostomy be considered in COVID-19 patients when prolonged } \\
\text { mechanical ventilation is anticipated. }\end{array}$ & $15 \%$ & $15 \%$ & \multicolumn{2}{|c|}{$69 \%$} & $\begin{array}{l}85 \% \\
\text { in favor }\end{array}$ \\
\hline $\begin{array}{l}\text { Recommendation } \\
2\end{array}$ & $\begin{array}{l}\text { There is insufficient evidence for recommending a specific timing for tracheostomy } \\
\text { in COVID-19 related respiratory failure. }\end{array}$ & $15 \%$ & $8 \%$ & $46 \%$ & $31 \%$ & $\begin{array}{l}77 \% \\
\text { in favor }\end{array}$ \\
\hline $\begin{array}{l}\text { Recommendation } \\
3\end{array}$ & $\begin{array}{l}\text { We suggest that in patients with COVID-19 related respiratory failure, either open } \\
\text { surgical tracheostomy (OST) or percutaneous dilatational tracheostomy (PDT) can be } \\
\text { performed in patients expected to require prolonged mechanical ventilation }\end{array}$ & $15 \%$ & & \multicolumn{2}{|c|}{$85 \%$} & $\begin{array}{l}100 \% \\
\text { in favor }\end{array}$ \\
\hline Remark 3-1 & $\begin{array}{l}\text { Utilization of techniques which minimize aerosolization is recommended when } \\
\text { performing tracheostomy. }\end{array}$ & $8 \%$ & & \multicolumn{2}{|c|}{$92 \%$} & $\begin{array}{l}100 \% \\
\text { in favor }\end{array}$ \\
\hline Remark 3-2 & $\begin{array}{l}\text { When open surgical tracheostomy (OST) is the technique chosen, it should be preferably } \\
\text { performed at the bedside in the ICU. }\end{array}$ & $15 \%$ & $15 \%$ & $31 \%$ & $38 \%$ & $\begin{array}{l}69 \% \\
\text { in favor }\end{array}$ \\
\hline $\begin{array}{l}\text { Recommendation } \\
4\end{array}$ & $\begin{array}{l}\text { We recommend that enhanced personal protective equipment (PPE) be used to mitigate } \\
\text { the risk of health care worker }(\mathrm{HCW}) \text { related infection during tracheostomy. }\end{array}$ & \multicolumn{4}{|c|}{$100 \%$} & $\begin{array}{l}100 \% \\
\text { in favor }\end{array}$ \\
\hline Remark 4 & $\begin{array}{l}\text { Tracheostomy is an aerosol generating procedure (AGP) and poses an infection risk } \\
\text { to HCW involved in the procedure. }\end{array}$ & $15 \%$ & & \multicolumn{2}{|c|}{$85 \%$} & $\begin{array}{l}100 \% \\
\text { in favor }\end{array}$ \\
\hline $\begin{array}{l}\text { Recommendation } \\
5\end{array}$ & $\begin{array}{l}\text { We suggest that in patients with COVID- } 19 \text { related respiratory failure, tracheostomy } \\
\text { is performed in a negative-pressure room, preferably in the ICU. As an alternative, } \\
\text { a negative-pressure room in the OR could be used, with special attention to minimizing } \\
\text { transportation-related risk of exposure. }\end{array}$ & $23 \%$ & & \multicolumn{2}{|c|}{$77 \%$} & $\begin{array}{l}100 \% \\
\text { in favor }\end{array}$ \\
\hline Remark 5 & $\begin{array}{l}\text { If negative pressure rooms are unavailable, the procedure could be performed in a } \\
\text { normal pressure room equipped with HEPA filters in the presence of a strict door policy. }\end{array}$ & \multicolumn{3}{|c|}{$54 \%$} & $46 \%$ & $\begin{array}{l}100 \% \\
\text { in favor }\end{array}$ \\
\hline $\begin{array}{l}\text { Recommendation } \\
6\end{array}$ & $\begin{array}{l}\text { We do not recommend routine RT-PCR testing (nasopharyngeal swab or lower } \\
\text { respiratory sample) prior to performing tracheostomy in patients with confirmed } \\
\text { COVID-19 related respiratory failure. }\end{array}$ & \multicolumn{2}{|c|}{$23 \%$} & \multicolumn{2}{|c|}{$77 \%$} & $\begin{array}{l}100 \% \\
\text { in favor }\end{array}$ \\
\hline Remark 6 & $\begin{array}{l}\text { There is insufficient evidence to recommend reverse transcriptase polymerase reaction } \\
\text { (RT-PCR) testing in patients with non-COVID-19 respiratory failure prior to tracheostomy. } \\
\text { If such testing is performed, we suggest that a lower respiratory sample (endotracheal } \\
\text { aspirate) rather than a nasopharyngeal swab be obtained. }\end{array}$ & $15 \%$ & j & $46 \%$ & $31 \%$ & $\begin{array}{l}77 \% \\
\text { in favor }\end{array}$ \\
\hline $\begin{array}{l}\text { Recommendation } \\
7\end{array}$ & $\begin{array}{l}\text { We recommend that in patients with COVID-19 related respiratory failure, tracheostomy } \\
\text { is performed by a team consisting of the least number of providers with the highest } \\
\text { level of experience. }\end{array}$ & \multicolumn{4}{|c|}{$100 \%$} & $\begin{array}{l}100 \% \\
\text { in favor }\end{array}$ \\
\hline Remark 7 & $\begin{array}{l}\text { We suggest that prior to the initiation of tracheostomy, a multidisciplinary group of } \\
\text { providers including the primary critical care team, palliative care, infectious disease, } \\
\text { the procedural and airway team utilize respective expertise to determine the goals of } \\
\text { care, patient selection, procedural considerations, as well as workflow to optimize safety } \\
\text { of both patient and HCW. }\end{array}$ & \multicolumn{2}{|r|}{$31 \%$} & \multicolumn{2}{|c|}{$62 \%$} & $\begin{array}{l}92 \% \\
\text { in favor }\end{array}$ \\
\hline $\begin{array}{l}\text { Recommendation } \\
8\end{array}$ & $\begin{array}{l}\text { We suggest that patients be maintained with a closed circuit while on mechanical } \\
\text { ventilation with a tracheostomy tube and with in-line suction. }\end{array}$ & \multicolumn{2}{|c|}{$23 \%$} & \multicolumn{2}{|c|}{$77 \%$} & $\begin{array}{l}100 \% \\
\text { in favor }\end{array}$ \\
\hline
\end{tabular}

Strongly Against $\square$ Weakly Against $\square$ Neutral $\square$ Weakly in Favor $\square$ Strongly in Favor

Figure 1 - Voting results for the recommendations and remarks. AGP = aerosol generating procedure; COVID-19=coronavirus disease 2019; HCW = health-care worker; HEPA = high-efficiency particulate air; OR = operating room; OST = open surgical tracheostomy; PDT = percutaneous dilatational tracheostomy; PPE = personal protective equipment; $R T-P C R=$ reverse transcription polymerase chain reaction.

to direct patient management during the COVID-19 pandemic. This document is structured around 8 questions. The panel elected to present this document as a consensus-based statement rather than a guideline given the limited evidence and the urgent need for direction on this topic for the medical community. Given the overall limited published evidence and the timeliness of this paper, the divergence from standard guideline development processes was intentional for expediency. The usual CHEST conflict of interest review process for consensus statements was waived because of the rapid development of this statement and the nature of the content. All authors reported their potential conflicts as part of the publication process.

This consensus statement is based on expert opinion from a panel of 13 pulmonary and critical care physicians subspecializing in interventional pulmonology. The panel included individuals from the United States from 13 different institutions from 10 of the 20 states with the highest number of confirmed COVID-19 cases reported in United States as of April 21, 2020. ${ }^{14}$ The panel included members with experience managing patients requiring tracheostomy during the COVID-19 pandemic. Each of the three professional societies selected their content experts through a transparent process. Specifically, CHEST selected its panel members by including two physicians working in the epicenter of the pandemic in the United States (L. A. and U. C.), a member of the Innovation subcommittee (H. B.), a member of the Bronchoscopy Domain Task Force (H. M.), and a representative from the CHEST Covid-19 Task Force (S. M.). A limitation of this statement is the lack of representatives from other relevant professional societies and health-care professionals involved in the care of patients with tracheostomies. The urgent need for direction on this topic for our community, the expected timely development, and fast release of this statement, however, did not allow for the initiation of new agreements with other professional societies.

The panel chairs (C. R. L., L. A., N. R. D., and S. M.) met during four conference calls to develop the questions, review submitted sections, and write the first manuscript draft. The entire panel was convened during a single session using a live audio and video interface on 
April 22, 2020 (Zoom Video Communications). The results and recommendations were presented, discussed, and refined. The panel independently and anonymously rated the appropriateness of the recommendations on a five-point Likert scale (Fig 1). We required $75 \%$ of the panel to respond to a vote for considering a specific recommendation. The strength of the recommendations is based on the degree of consensus resulting from the modified Delphi method.
At least $70 \%$ agreement on the direction of a recommendation was considered consensus. A threshold of $\geq 80 \%$ for agreement was required for each item to reach strong consensus (Fig 1).

We make a suggestion when referring to an action for physicians to consider and a recommendation when referring to a preferred choice of action.

\section{Results}

\section{Outcomes of Tracheostomy}

\section{We suggest that tracheostomy be considered in coronavirus disease 2019 (COVID-19) patients when prolonged mechanical ventilation is anticipated.}

Data are lacking on the subject of clinical utility of tracheostomy vs prolonged intubation and mechanical ventilation in patients with COVID-19 respiratory failure. In the medical and surgical literature reviewed by our team, prolonged intubation and late tracheostomy were grouped together and were defined as 10 to 15 days after initiation of mechanical ventilation. One study from New York University Langone Health showed that $33 \%$ of patients who underwent percutaneous dilatational tracheostomy (PDT) at a mean of 10 days were liberated from mechanical ventilation. ${ }^{7}$ The followup of 18 days is too short to comment on how tracheostomy impacts long-term outcomes in this patient population, especially in the absence of a control group.

We surveyed the literature reporting the benefits of tracheostomy regarding ICU length of stay, hospital stay, mortality, and complications such as ventilatorassociated pneumonia (VAP). A prospective randomized study comparing 120 patients with early (within $48 \mathrm{~h}$ ) to late tracheotomy (14-16 days) in critically ill medical patients demonstrated that the early group had lower mortality, less pneumonia, and fewer accidental extubations compared with late tracheostomy. ${ }^{15}$ A prospective randomized controlled trial compared early (day 3) vs delayed (day 15) tracheostomy in surgical ICU adult patients anticipated to require prolonged mechanical ventilation via endotracheal intubation. The study concluded that the early PDT resulted in more ventilator-free, sedationfree, and ICU-free days; higher successful weaning and ICU discharge rate; and lower incidence of VAP, but did not change the cumulative 60-day incidence of death in the patients' anticipated requiring prolonged mechanical ventilation. ${ }^{16}$ A large Cochrane Database systematic review from 2015 comparing early (2-10 days after intubation) to late ( $>10$ days after intubation) tracheostomy in critically ill adults included eight randomized controlled trials with almost 2,000 participants. ${ }^{17}$ This analysis did not show a lower VAP incidence, but there was a lower mortality rate in the early compared with the late tracheostomy group (number needed to treat for an additional beneficial outcome, approximately 11). ${ }^{17}$ A large retrospective study of almost 125,000 tracheostomies did show an association between early tracheostomy and decreased rate of sepsis and VAP. ${ }^{18}$ Another prospective randomized study from surgical critical care units with slightly different criteria for early ( $<4$ days) and late $(>$ 10 days) did not find any statistically significant difference in 30-day or 2-year mortality. ${ }^{19}$ The available literature suggests potential benefits of tracheostomy compared with prolonged mechanical ventilation, but the data on mortality and VAP, however, remain unclear.

Tracheostomy appears to be clinically useful in patients with COVID-19 when prolonged ventilator support is anticipated. The data from the COVID-19 pandemic are limited, but the procedure was performed safely for patients and operators. ${ }^{7}$ Most data reviewed preCOVID-19 are from medical and surgical clinical trials in critically ill patients with ARDS. The information from publications suggests that tracheostomy could potentially offer better outcomes including ventilatorfree days, shorter stay in the ICU, shorter stay in the hospital, and perhaps reduced incidence of hospitalacquired pneumonia when compared with prolonged mechanical ventilation. Therefore, we suggest that tracheostomy be considered in patients with COVID-19 when mechanical ventilation is anticipated to be $>10$ to 15 days.

\section{Timing of Tracheostomy}

\section{There is insufficient evidence for recommending a specific timing for tracheostomy in COVID-19 related respiratory failure.}

Conventionally, in the medical ICUs, tracheostomy has been performed in patients with ongoing mechanical ventilatory needs, 2 to 3 weeks after endotracheal intubation. The decision regarding timing of 
tracheostomy, while dependent on the understanding of disease pathogenesis, is composed of a variety of factors including patient and family preferences, expected outcomes, and the likelihood of weaning from mechanical ventilation. ${ }^{20}$ Early tracheostomy has justifiable benefits, including lower sedation requirements and increased patient comfort. ${ }^{21}$ Many studies have demonstrated shorter duration of mechanical ventilation and ICU stay with early tracheostomy, ${ }^{15,22,23}$ but others have not. ${ }^{21,24,25}$ As previously mentioned, published literature does not clearly support a mortality benefit ${ }^{19,23,26,27}$ or reduction of VAP with early tracheostomy. ${ }^{22,23}$ Determining a patient's prognosis in the ICU remains challenging. In a large multicenter trial, 55\% of patients randomized to a late tracheostomy group never received the intervention. ${ }^{19}$ Therefore, committing patients to early tracheostomy could lead to procedures in patients who may not need it altogether during the course of their illness. The procedural, stomal, and cuff-related complications associated with tracheostomy should be considered. During the current pandemic, transmission of viral illness to HCWs performing AGPs relative to timing is also a consideration. ${ }^{12}$

Based on available published literature, the optimal timing of performing a tracheostomy in critically ill patients still remains debatable. Specifically, there are no studies addressing the optimal timing of tracheostomy in patients infected with severe acute respiratory syndrome coronavirus 2019 (SARS-CoV-2). There is little we can infer from case series published during the 2003 SARS outbreak because the timing of the procedure was not documented. ${ }^{6}$ The initial experience from New York University Langone Health suggests the feasibility and safety of a modified bedside PDT performed at a mean of 10 days from intubation in patients with confirmed COVID-19. After a mean follow-up posttracheostomy of 11 days, $33 \%$ of patients were liberated from mechanical ventilation. ${ }^{7}$ Early tracheostomy in carefully selected patients with COVID19 may optimize ICU resources in a system that is experiencing an escalating number of critically ill patients. Faster liberation from mechanical ventilation and discharge from the ICU along with decreased use of neuromuscular blocking agents and sedatives may be helpful in circumstances where there are critical resource constraints. In addition, because viral clearance is slower in critically ill patients, the risk of transmission of infection to HCWs should not be the main basis for deciding between early or late tracheostomy. ${ }^{3,10,12}$ In a study of hospitalized patients, median duration of viral shedding, as detected in upper respiratory specimens, was 20 days in survivors, with the virus being detectable until death in nonsurvivors. ${ }^{28}$ In another study on critically ill patients, viral RNA was detectable in lower respiratory tract specimens in $69 \%$ of patients beyond 28 days from symptom onset. ${ }^{3}$ These data argue against waiting 3 weeks for performing the tracheostomy.

However, published reports from China, Italy, and the United States demonstrate that COVID-19 has a high ICU mortality. ${ }^{4,5,28-32}$ ICU mortality in studies with longer follow-up rates is $42 \%$ and $78 \%{ }^{28,29}$ In addition, $12 \%$ to $58 \%$ of patients remain in the ICU at the end of their respective follow-up periods. ${ }^{4,50-32}$ Institutions now face the decision of pursuing a tracheostomy in many patients with COVID-19, most of whom may require prolonged mechanical ventilation. ${ }^{5}$ In a study on 1,591 critically ill patients with COVID-19 from Italy, $58 \%$ of patients were still in the ICU at the end of their follow-up (minimum of 7 days). ${ }^{5}$ The median ICU length of stay in those who survived and those who died in the ICU was 8 and 7 days, respectively. These data suggest that waiting until at least the second week to assess a patient's ICU course may be prudent because many patients would have by then declared their disease trajectory.

The existing evidence regarding early vs late tracheostomy in critically ill patients in medical ICUs does not favor one approach. There is no generalizable best timing to perform tracheostomy in patients with COVID-19-related respiratory failure requiring mechanical ventilation. There is insufficient evidence to suggest performing a tracheostomy in the second week of mechanical ventilation or later, and this decision should be individualized based on the physician's best estimate regarding prognosis and factoring in institutional critical care resource constraints. The lack of COVID-19 tracheostomy-related evidence, the conflicting published data on early vs late tracheostomy in general, and the unique COVID-specific scenarios of HCW exposure and resource utilization in stretched systems make it impossible to provide specific guidance on timing of tracheostomy.

\section{Tracheostomy Technique}

3. We suggest that in patients with COVID-19 related respiratory failure, either open surgical (OST) or percutaneous dilatational tracheostomy (PDT) can be performed in patients expected to require prolonged mechanical ventilation. 
TABLE 2 ] Pros and Cons of PDT vs OST

\begin{tabular}{|c|c|c|c|}
\hline \multicolumn{2}{|c|}{ OST } & \multicolumn{2}{|c|}{ PDT } \\
\hline Pros & Cons & Pros & Cons \\
\hline $\begin{array}{l}\text { No need for bronchoscopy } \\
\text { or access through the } \\
\text { mouth }\end{array}$ & $\begin{array}{l}\text { May require more health- } \\
\text { care workers in the room }\end{array}$ & $\begin{array}{l}\text { Less bleeding-no need for } \\
\text { planned cautery }\end{array}$ & $\begin{array}{l}\text { Not possible when } \\
\text { significant pretracheal } \\
\text { vessels identified by } \\
\text { ultrasound } \\
\text { Other anatomic features } \\
\text { may not be amenable to } \\
\text { PDT }\end{array}$ \\
\hline $\begin{array}{l}\text { Entry in the trachea may be } \\
\text { quicker without need for } \\
\text { dilation }\end{array}$ & $\begin{array}{l}\text { Aerosolization may occur } \\
\text { during cautery and suction } \\
\text { usage }\end{array}$ & $\begin{array}{l}\text { Generally performed at } \\
\text { bedside in the ICU }\end{array}$ & Need for bronchoscopy \\
\hline \multirow[t]{2}{*}{$\begin{array}{l}\text { ETT cuff pushed caudally } \\
\text { remains inflated during } \\
\text { the incision portion of the } \\
\text { tracheotomy, further } \\
\text { minimizing time of } \\
\text { tracheal patency and risk } \\
\text { of aerosolization }\end{array}$} & $\begin{array}{l}\text { Negative pressure capability } \\
\text { may not be available in the } \\
\text { OR; although, it may be } \\
\text { performed at bedside in } \\
\text { the ICU, it may require } \\
\text { more logistical planning }\end{array}$ & $\begin{array}{l}\text { May be performed by } \\
\text { nonsurgically trained } \\
\text { physicians }\end{array}$ & $\begin{array}{l}\text { Potential loss of airway } \\
\text { because of accidental } \\
\text { premature extubation } \\
\text { before establishing } \\
\text { definitive airway, } \\
\text { requiring emergent } \\
\text { reintubation and aerosol } \\
\text { exposure to personnel }\end{array}$ \\
\hline & $\begin{array}{l}\text { May require transport to the } \\
\text { OR through hallways with } \\
\text { theoretical risk of } \\
\text { accidental disconnection } \\
\text { from the ventilator and } \\
\text { contamination } \\
\text { The stoma in an OST might } \\
\text { be larger when compared } \\
\text { with PDT and it may take } \\
\text { longer time to close after } \\
\text { decannulation, therefore } \\
\text { leading to longer } \\
\text { aerosolization }\end{array}$ & $\begin{array}{l}\text { New modified techniques } \\
\text { described with } \\
\text { bronchoscopy alongside } \\
\text { the ETT which may } \\
\text { reduce aerosolization and } \\
\text { reduce the number of } \\
\text { personnel at bedside or } \\
\text { use with ultrasound alone } \\
\text { to reduce need for } \\
\text { bronchoscopy }\end{array}$ & \\
\hline
\end{tabular}

$\mathrm{ETT}=$ endotracheal tube; $\mathrm{OR}=$ operating room; OST = open surgical tracheostomy; PDT = percutaneous dilatational tracheostomy.

Remarks: Utilization of techniques which minimize aerosolization is recommended when performing tracheostomy.

Tracheostomy is considered an AGP, and in COVID-19related respiratory failure, it can potentially increase the risk of transmission to HCWs. The optimal technique in these patients remains unknown because both procedures have pros and cons, as summarized in Table 2. A metaanalysis and a systematic review of the pre-COVID literature suggest that PDT results in lower rates of wound infection and bleeding when compared with open surgical tracheostomy (OST) in the operating room. ${ }^{33}$ During the SARS outbreak, mostly OST was performed on infected patients, with several reports documenting no infection to the HCWs when enhanced personal protective equipment (PPE) was being used. ${ }^{6}$ At that time, it was thought that PDT involved more extensive airway manipulation that resulted in an increased aerosolization risk. ${ }^{34,35}$ Since then, the techniques for PDT have continued to evolve. Operators now include ultrasonography as a reliable method of delineation of anatomic structures, further improving technique. ${ }^{36-39}$ Because of its performance at the bedside and safety profile, bronchoscopy-guided PDT has become the preferred practice in many institutions. ${ }^{33,40}$ PDT has been demonstrated to be at least as safe as the conventional surgical approach in most critically ill patients. There is also emerging evidence from this pandemic that a novel modified technique of PDT in which the endotracheal tube (ETT) cuff remains inflated and in the distal trachea and the bronchoscope inserted next to the $\mathrm{ETT}^{7}$ can be safely performed with no major immediate complications for patients and no documented infection to HCWs. This modified technique may be more feasible with earlier tracheostomies before the development of laryngeal edema that may preclude scope insertion alongside the ETT.

To date, it is unclear, however, which technique is safer for patients with COVID-19 while reducing transmission to HCWs. 
In our literature search, we identified case series from the 2003 SARS outbreak and statements from professional societies or institutions regarding tracheostomy in the COVID-19 pandemic. ${ }^{9,41}$ Most of these articles comment on the aerosolization potential of each procedure to HCWs and the various techniques described to minimize such risk (Table 3). In these position or perspective papers, PDT is considered a procedure that involves more extensive airway manipulation because it uses bronchoscopy and dilation of the tracheal intercartilaginous space. These factors may indeed result in an increased aerosolization risk and exposure to the operators and ancillary personnel. ${ }^{6}$ On the other hand, PDT is a procedure that offers the ease of performing it in the ICU in a negative pressure (NP) room, minimizing the risk associated with transporting a patient with COVID-19 to the operating room. PDT generally results in less bleeding and therefore less need for cautery (often needed with OST), which itself carries a risk of aerosolizing particles. ${ }^{42}$ PDT typically may require fewer HCWs involved in the procedure when compared with OST. Finally, the role of ultrasonography has been highlighted as a tool during PDT in patients with COVID-19, thereby reducing the need for bronchoscopic guidance with its potential risk of aerosolization. In fact, three pre-COVID-19 studies demonstrated shorter procedure duration and lower hemorrhage using ultrasound compared with bronchoscopic guidance during PDT. ${ }^{36-39}$

With OST, the use of bronchoscopy is avoided; therefore, aerosolization risks may be diminished. There is the added possible risk of aerosolization with cautery and use of suction. Logistical considerations, such as space and personnel, should be carefully considered when this procedure is performed at the bedside because some operating rooms do not have NP capabilities. In these circumstances, meticulous planning with institutional-specific infection control teams and simulated rehearsing should be considered by the operating team. Performing OST at the bedside may be preferred to avoid aerosolization because of inadvertent disconnection of the ventilator circuit during patient transport.

Regardless of technique, the portions of the tracheostomy procedure with the highest risk of aerosolization to personnel are during ETT repositioning with cuff deflation, the incision portion of the tracheotomy into the anterior tracheal wall, dilation of the trachea, and the tracheostomy cannula insertion. The operators should strive to implement techniques that are considered best practices to minimize aerosolization. These include ensuring complete neuromuscular blockade, packing the oropharynx, performing apnea at times when aerosolization risk is highest or when manipulating the ETT, reducing or avoiding the use of suction and diathermy, and using gauze or a sponge at the stoma site. All techniques should ideally be performed at the patient's bedside to avoid unnecessary transfers to the operating room where the risk of ventilator circuit interruption and exposure to other areas of the hospital may occur.

Our recommendation highlights the fact that the optimal technique, OST or PDT, is unknown because there are pros and cons to both procedures. Therefore, the technique used should be based on individual institutional expertise and defined protocols. Not every institution has the ability to perform PDT or bedside OST. Importantly, this recommendation outlines that OST is not absolutely necessary, as once thought during the SARS outbreak. We recognize that institutions may change their practice as more evidence is emerging during or after this pandemic. The type of tracheostomy (PDT vs OST) should be at the discretion and expertise of the performing operator and the ICU team.

\section{Risk of Infection to HCWs and the Role of Enhanced} PPE

4. We recommend that enhanced personal protective equipment (PPE) should be used to mitigate the risk of HCW infection during tracheostomy.

Remarks: Tracheostomy is an aerosol generating procedure (AGP) and poses an infection risk to $\mathrm{HCW}$ involved in the procedure.

HCWs performing AGPs are at occupational risk for infectious diseases transmitted from patients, sometimes despite existing safety protocols. ${ }^{12}$ COVID-19 is transmitted via respiratory droplets, and interventions which exacerbate the production of droplets and aerosols could exacerbate the risk of infection. ${ }^{43}$ The Chinese Center for Disease Control and Prevention statistics indicate that HCWs represented $3.8 \%$ of the reported cases. Of these, $14.8 \%$ had severe disease and the overall mortality rate was $0.6 \%{ }^{44-46}$ In Italy, approximately $20 \%$ of responding HCWs were infected. ${ }^{47}$ As of April 9, 2020, per the Centers for Disease Control and Prevention (CDC) in the United States, 9,282 HCWs have been infected with SARSCOV-2, accounting for $11 \%$ of all the reported cases, with 27 reported deaths. More than one-half of these 
TABLE 3 ] General Risk Reduction Best Practices

General Risk Reduction Best Practices

1. Equipment and medications should be preplanned with checklist and procedure kits prior to entering the room.

2. Avoid using carts in the room to reduce the need to undergo decontamination. Consider a disposable bronchoscope.

3. Universal protocol and time out may be performed outside the room with procedure team followed by appropriate donning of enhanced PPE per institutional protocol.

4. Use of ultrasound to assess anatomy and point of entry (use standard decontamination protocol of durable equipment).

5. Deep sedation and neuromuscular blockers should be used for the procedure to minimize cough and agitation.

6. Before start, perform a trial of apnea to mimic apnea.

a. Withhold ventilation (apnea).

b. Discontinue positive end-expiratory pressure.

c. Increase the $\mathrm{FIO}_{2}$ to prevent desaturation, for a duration of $30 \mathrm{~s}$ to $1 \mathrm{~min}$.

If apnea is not tolerated, reduce the ventilatory pressures and respiratory frequency to minimize the risk of aerosolization. Otherwise, consider deferring the procedure until ventilatory requirements are optimized.

7. Key intervals where apnea must be performed during a traditional bronchoscopic-guided percutaneous dilational tracheostomy are as follows:

- When the bronchoscope adaptor is added to the circuit.

- Prior to inserting the bronchoscope into the ETT.

- During the pullback of the ETT with cuff deflation.

- Time of insertion of the introducer needle, angiocatheter, dilation, and insertion of the tracheostomy tube, bronchoscopic confirmation of placement, until connected to closed circuit connection with ventilator.

- Removal of the ETT from oropharynx.

8. The oropharynx and the hypopharynx may be packed. A suction tip may be placed in the mouth to lessen the risk of aerosolization of oral secretions during the ETT pullback.

9. During the procedure, place a moist gauze or sponge around the guidewire, during dilation, and neck stoma as needed.

10. Ultrasound can be incorporated into PDT to avoid the need for bronchoscopic guidance. Sonography equipment will need to be decontaminated at the end of the procedure. Additionally, a modified PDT technique with placement of bronchoscope alongside the ETT while advancing the ETT below the intended stomal point of entry might reduce aerosolization.

11. During an open tracheostomy, in addition to the aforementioned steps using apnea during ETT manipulation and prior to incision into the anterior wall of the trachea, avoid or minimize the use of diathermy and suction because it carries a risk of aerosolizing particles.

12. Place a petrolatum gauze dressing at the site of the fresh stoma until it heals to prevent aerosolization or air leak.

See Table 1 and 2 legends for expansion of abbreviations.

HCWs reported contact with patients with COVID-19 only in health-care settings. The total number of cases of HCWs infected with COVID-19 in the United States may be an underestimation because only $16 \%$ of respondents were asked to comment on their health-care exposures. ${ }^{13}$

The scientific evidence for the creation of aerosols associated with tracheostomy, the load of viable viruses within the aerosols, and the precise mechanism of transmission to the host have not been clearly studied. However, a systematic review of 10 studies from the 2003 SARS outbreak suggests that tracheostomy has an OR of 4.2 for risk of transmission to HCWs. ${ }^{48}$ There is evidence that personnel education and the use of PPE are associated with a decreased risk of transmission of
SARS. ${ }^{49}$ Most SARS cases involved nosocomial transmission in hospitals via AGPs. ${ }^{50}$ This risk is maximal during intubation, tracheostomy, or open airway procedures, where the exposure will occur in close proximity, often involving positive pressure ventilation. Understanding how to mitigate these risks is critical. ${ }^{51}$ Studies specifically evaluating the risk of infection to the HCWs performing these procedures in COVID-19 are not available. However, one of the earliest reports from Wuhan, China, found that among the first 138 consecutive patients hospitalized, 40 were HCWs. ${ }^{4}$ During the SARS outbreak of 2003 in Canada, 51\% of the 438 cases were HCWs, and three died from SARS-related causes. ${ }^{49}$ Although the figures are concerning, other data suggest that by respecting the personal protective measures, HCWs can stay safe. Although standard PPE is 
essential (N95 mask, goggles or face shield, surgical gown, and gloves), the case series of tracheostomies performed in five health-care institutions in Singapore, Hong Kong, and Canada during the SARS outbreak also document that in addition to standard PPE, enhanced PPE measures were applied ranging from the addition of face shields to standard PPE or powered air-purifying respirators. All members of the surgical teams remained healthy after performing a total of 23 tracheostomy procedures. ${ }^{6}$ From this COVID-19 pandemic, published data are limited. A case report of early COVID-19 experience from

Singapore $^{52}$ revealed that none of the 41 HCWs who took care of a patient with severe pneumonia before diagnosis of COVID-19 became infected themselves or developed symptoms. These HCWs had been present during intubation and extubation of the patient and they were present for at least $10 \mathrm{~min}$ at a distance of $<2 \mathrm{~m}$ from the patient, with $85 \%$ wearing a surgical mask and the remainder wearing N95 masks. Similarly, at New York University, a team composed of eight HCWs reported 98 PDTs. The personnel strictly respected the use of enhanced PPE and no members tested positive or developed COVID-19 symptoms. ${ }^{7}$ As of this writing, there are no hard data regarding aerosolization risk between OST and PDTs.

In summary, the data on the risk of HCW infection during tracheostomy are mixed. The available data suggest that the rate of infection, when enhanced PPE measures are used, is considerably lower than when they are not used or are used improperly. ${ }^{52,53}$ Although the specific risk associated with tracheostomy during COVID-19 is not known, tracheostomy is one of the high-risk AGPs, and prior SARS experience suggests that adequate protection is essential to prevent HCWs from contacting the infection. In addition to PPE, other ways of mitigating the risks for HCWs involved in the tracheostomy procedure include location and technique.

\section{Location of Tracheostomy Procedure}

\section{We suggest that in patients with COVID-19 related respiratory failure, tracheostomy is performed in a negative-pressure room, preferably in the ICU. As an alternative, a negative-pressure room in the OR could be used, with special attention to minimizing transportation-related risk of exposure.}

Remarks: If negative pressure rooms are unavailable, the procedure could be performed in a normal pressure room equipped with HEPA filters in the presence of a strict door policy.
Performing OSTs in the operating room is a common practice worldwide. However, during previous SARS outbreaks, OST at the bedside in the ICU has evolved as an alternative approach. ${ }^{6,35}$ It has been suggested that performing tracheostomies in the ICU rooms minimizes the risk of exposure of HCWs and decreases aerosol generating maneuvers (eg, disconnection of mechanical ventilator circuit) caused by transportation of patients to the operating room. Furthermore, the presence of NP rooms, which are recommended for this type of procedure, ${ }^{35,51,54,55}$ has historically been limited in the operating room. ${ }^{56}$ However, challenges to performing open tracheostomies in ICU rooms have been described in relationship to limited space, possible suboptimal patient positioning, and limited movement of the surgical equipment. ${ }^{6,42,56}$ Nevertheless, the available published data on bedside tracheostomies in SARS-CoV and the initial reports from COVID-19 were successful.

Our literature search found no study that compares tracheostomy performed in the operating room vs ICU room in COVID-19-related respiratory failure. Six nonrandomized studies were found about tracheostomy in the SARS-CoV population, ${ }^{34,35,56-58}$ with three of them being case series that included three or more patients. ${ }^{35,42,58}$ The other three were single case reports. There was only one case report that included infection by SARS-CoV-2 2019. ${ }^{57}$ In these studies, 24

tracheostomies were performed successfully. All of them were done using OST technique. The use of a NP room was a common characteristic in all procedures. Only two procedures were performed in the operating room (case reports), ${ }^{34,57}$ and the rest were performed at bedside in ICU rooms. In the largest case series, 15 tracheostomies were performed at bedside in the ICU rooms to avoid transportation of patients and to minimize exposure. ${ }^{35}$ None of the studies reported complications because of the procedure.

ICU rooms with NP that have an anteroom adjacent to it are ideal to allow appropriate donning and doffing of PPE for the surgical team. If the operating room is used, the room should have its own ventilation system and be separated from the main operating room. ${ }^{59}$ The use of portable ventilators with enough distance from the transport team and minimizing disconnection of ventilator circuit during the process are extremely important to decrease exposure of HCWs. ${ }^{35}$ Small highefficiency particulate air (HEPA) filters attached to ventilator circuit could be used to minimize aerosol dissemination. The use of specific routes and dedicated elevators to transport patients could minimize 
exposure. ${ }^{35}$ The use of a special team for transportation (different from the surgical team) could allow time for the surgical team to do appropriate donning and doffing before and after the procedure, ${ }^{34}$ but it also increases the number of people exposed to the patient.

Recommendations by the CDC establish that an airborne infection isolation room, formerly called NP isolation room, should be used for aerosol generating procedures. ${ }^{7,59}$ Although not specifically mentioned, based on the CDC recommendations and prior experience, positive pressure rooms should be avoided for these procedures, if possible. This measure minimizes the concentration of aerosol inside the room, which leads to less exposure of the operators and less aerosol dissemination outside the room when the door is opened. In the absence of NP rooms, Chee et al. ${ }^{35}$ described the use of single rooms, with locked and sealed doors (with tape) as an alternative (strict door policy). The use of small HEPA filters attached to the airway tubing/ventilator circuit ${ }^{60}$ and large HEPA filters for the room have been described in case reports to minimize aerosol dissemination. Reports from the COVID-19 pandemic suggest that PDT has been successfully performed at the bedside in the ICU in New York City, without any documented COVID-19 transmission to HCWs. ${ }^{32}$ Exercising a standard process of donning and doffing PPE including ongoing education is extremely important and enhances the protection of the staff. ${ }^{35}$ Although the use of PPE has been reported to limit communication (hearing) among members of the team, ${ }^{42,56}$ no complications were reported as a consequence of wearing PPE. In addition, the use of NP canopies is currently under investigation.

The review of existing studies from prior viral outbreaks and the frontline experience from the COVID-19 pandemic are based on these recommendations. Tracheostomy should ideally be performed at the bedside in the ICU, with patients being located in NP rooms or normal pressure rooms with strict door policy with the use of HEPA filters.

\section{Role of Preprocedural COVID-19 Testing}

\section{We do not recommend routine RT-PCR testing (nasopharyngeal swab or lower respiratory sample) prior to performing tracheostomy in patients with confirmed COVID-19 related respiratory failure.}

Remarks: There is insufficient evidence to recommend RT-PCR testing in patients with non-COVID-19 respiratory failure prior to tracheostomy. If such testing is performed, we suggest that a lower respiratory sample (endotracheal aspirate) rather than a nasopharyngeal swab be obtained.

Diagnostic testing to identify infected individuals is considered essential to the control of the global pandemic of COVID-19. Important gaps remain in screening asymptomatic people during the incubation phase, and in the accurate determination of the live viral shedding during convalescence. ${ }^{61}$ It is critical to minimize the risk of transmission of infection to HCWs during the procedural and postprocedural care. ${ }^{62}$ Guidance on repeat testing prior to AGPs and how it impacts duration of isolation precautions, utilization of available resources, and discharge management is lacking.

Evidence is emerging of active viral replication in the upper respiratory tract tissues, given successful live virus isolation from throat swabs. ${ }^{63}$ Reports of prolonged respiratory viral shedding up to 55 days $^{3,64,65}$ may be concerning for high transmissibility, and puts HCWs at high risk for contracting COVID-19 infection. However, as with SARS-CoV-1, detection by means of reverse transcription polymerase chain reaction (RT-PCR) assays may not predict infectivity. ${ }^{66}$ Hospitalized patients demonstrating clinical improvement, who are positive on RT-PCR testing, likely have viral shedding, and warrant continued airborne and enhanced droplet and contact precautions. Several authorities have recommended obtaining at least two negative upper respiratory tract samples, collected at intervals of $\geq 24 \mathrm{~h}$ to document SARS-CoV-2 clearance. ${ }^{67,68}$ Real-time RTPCR remains the reference standard for the initial diagnosis of COVID-19 infection and follow-up testing for its clearance; however, the test has variable sensitivity in clinical practice ranging from $37 \%$ to $71 \% .{ }^{69,70}$ Also, the detection rate in clinical specimens varies with the site, with a few studies suggesting higher sensitivity in lower respiratory specimens (endotracheal aspirate or BAL) compared with nasopharyngeal or oropharyngeal swabs. ${ }^{3,63,71,72}$ This makes nasopharyngeal swab RTPCR testing less reliable, especially during the convalescent phase (14-21 days) of the illness. Because most patients undergoing tracheostomy are likely to show signs of clinical recovery and are in the convalescent phase, based on the evidence previously discussed, results of repeat testing are unlikely to impact decision-making regarding infection control practices while in the hospital setting. We did not find literature supporting testing prior to the procedure in nonCOVID-19-related respiratory failure. A negative test may affect management in these patients because 
TABLE 4 ] Summary of Posttracheostomy Care of Patients With COVID-19

\begin{tabular}{|c|c|}
\hline Society & Recommendations \\
\hline $\begin{array}{l}\text { Ear, Nose, and Throat Surgery in the } \\
\text { United Kingdom }\end{array}$ & $\begin{array}{l}\text { - Avoid changing the tracheostomy tube until COVID-19 has passed } \\
\text { - Cuff to remain inflated and check for leaks } \\
\text { - Make every effort not to disconnect the circuit } \\
\text { - Only closed in-line suctioning should be used }\end{array}$ \\
\hline Government of Canada & $\begin{array}{l}\text { - AGPs should be performed on patients suspected or confirmed with infection } \\
\text { only if medically necessary } \\
\text { - Strategies to reduce aerosol generation should be applied } \\
\text { - The number of HCWs present during AGPs should be limited to those essential } \\
\text { for patient care and support }\end{array}$ \\
\hline $\begin{array}{l}\text { American Academy of Otolaryngology- } \\
\text { Head and Neck Surgery }\end{array}$ & $\begin{array}{l}\text { - Limit the number of providers participating in tracheotomy procedural and } \\
\text { postprocedural management } \\
\text { - Avoid circuit disconnections and suction via closed circuit } \\
\text { - Place a HME with viral filter or a ventilator filter once the tracheotomy tube is } \\
\text { disconnected from mechanical ventilation } \\
\text { - Delay routine postoperative tracheotomy tube changes until COVID-19 testing } \\
\text { is negative }\end{array}$ \\
\hline $\begin{array}{l}\text { Canadian Society of Otolaryngology- } \\
\text { Head and Neck Surgery }\end{array}$ & $\begin{array}{l}\text { - Avoid open suction and instead use closed, in-line suction whenever possible } \\
\text { - Avoid repeated suctioning and disconnection of the ventilator circuit } \\
\text { - Use an HME with HEPA-level filter (preferred) to provide humidity, reduce } \\
\text { secretions with minimal increase in perceived respiratory resistance in the } \\
\text { ventilator circuit or on the ventilator exhaust portion; monitor filter for } \\
\text { obstruction risk } \\
\text { - Minimize nebulization, instillation of fluids } \\
\text { - Avoid all unnecessary examinations or procedures including decannulation } \\
\text { - Fortil the patient is considered COVID-19 negative } \\
\text { changes during pandemic }\end{array}$ \\
\hline $\begin{array}{l}\text { Speech Language and Audiology } \\
\text { Canada }\end{array}$ & $\begin{array}{l}\text { - Identify the minimum number of people required to safely conduct a session } \\
\text { - Consider bundling care with other health-care professionals } \\
\text { - Carefully consider equipment use and discuss with infection control services to } \\
\text { ensure it can be properly decontaminated } \\
\text { - Avoid moving equipment between infectious and noninfectious areas } \\
\text { - Wherever possible, single patient use, disposable equipment is preferred }\end{array}$ \\
\hline
\end{tabular}

AGP = aerosol generating procedure; HEPA = high-efficiency particulate air; HME = heat moisture exchanger. See Table 1 legend for expansion of other abbreviations.

operators may choose not to use enhanced PPE or strictly apply the described techniques for minimizing aerosolization. We think that in the context of an ongoing pandemic, it is prudent to perform all AGPs with enhanced PPE. This is especially important given the variability in the sensitivity of test results because of timing of testing and type of testing kits.

Pretracheostomy retesting in patients with COVID-19 and testing in patients without COVID-19 may facilitate decisions regarding duration and type of isolation precautions and must follow local guidelines for infection control practices.

We based the remarks to this recommendation on the limited published evidence suggesting a greater number of positive RT-PCR tests and a higher viral respiratory load in lower respiratory tract samples compared with nasopharyngeal swabs. ${ }^{3,71,72}$ Additionally, data from a well-conducted study suggest a higher viral load and a slower decline in RNA concentration in lower respiratory tract samples compared with the nasopharyngeal swabs. ${ }^{63}$ We recognize that the test results depend on a wide variety of factors including sample collection technique, transportation, processing, and method used for RT-PCR testing. Therefore, when obtained, a lower respiratory sample should be processed using validated tests available at individual institutions.

\section{Role of a Multidisciplinary Team}

\section{We recommend that in patients with COVID-19} related respiratory failure, tracheostomy is performed by a team consisting of the least number of providers with the highest level of experience.

Remarks: We suggest that prior to the initiation of tracheostomy, a multidisciplinary group of providers including the primary critical care team, palliative care, infectious disease, the procedural and airway team 


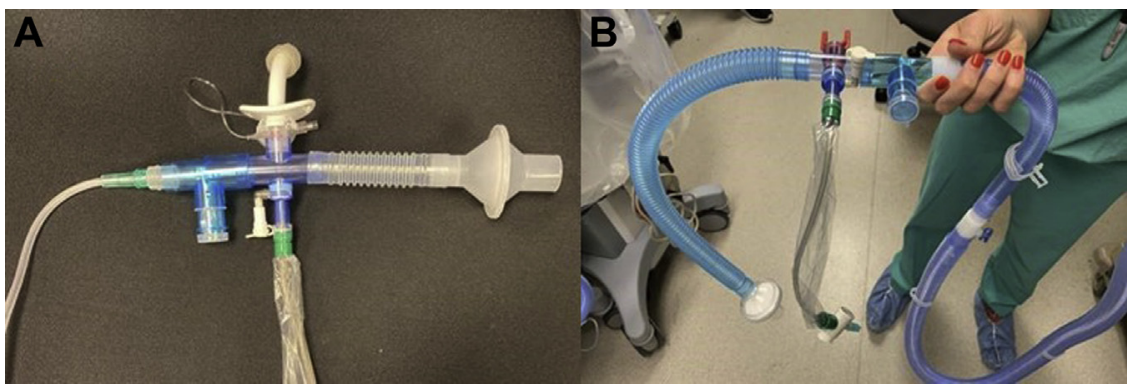

Figure $2-A-B$, Closed circuit setup using a heat moisture exchanger with viral filter and in-line suction can be used to minimize aerosol generation. Suggested setup for patients without $(A)$ and with (B) high oxygen requirements. Credit: Jhanvi Soni, RRT, Michelle Prickett, MD and Lisa Wolfe, $M D$.

utilize respective expertise to determine the goals of care, patient selection, procedural considerations, as well as workflow to optimize safety of both patient and HCW.

Prior to COVID-19, the practice of PDT was increasingly performed by multidisciplinary teams at large tertiary care hospitals. Multidisciplinary PDT teams often include nonsurgical and surgical physicians (otolaryngologists, trauma surgeons, general surgeons, thoracic surgeons, interventional pulmonologists, and intensivists), anesthesiologists, nurses, respiratory therapists, and speech and language pathologists. These teams have reported improved outcomes, including the incidence of airway bleeding, physiological disturbances, and efficiency of care delivery. ${ }^{73,74}$ Implementation of a multidisciplinary PDT service was shown to result in a marked decrease in major complications

(25.4\% preimplementation and $4.9 \%$ postimplementation) and a reduction in wait time for the performance of tracheostomy (2.6 days preimplementation and 1.3 days postimplementation). ${ }^{74}$ Several other reports of tracheostomy-centered multidisciplinary teams have been published and support these findings. ${ }^{75-78}$

Review of the literature revealed several articles supporting the use of a multidisciplinary team; however, there are limited or no data specifically evaluating this paradigm in the setting of pandemic illness. We found two case series ${ }^{42,55}$ and four editorials/technical communications/systematic reviews of the literature. ${ }^{34,79-81}$ Both case series discussed tracheostomy during the SARS-CoV epidemic of 2003. The systematic reviews included one from the SARS-CoV epidemic and three pertaining to the current COVID-19 pandemic. All the papers discussed the need to minimize the number of procedural team members because of concerns for pathogen exposure and conservation of PPE, with the number of personnel ranging between three and five. Four of the six papers recommended a three-person team consisting of one to two surgeons, one person to manage the ventilator/ETT, and if there was only one surgeon performing the procedure one additional staff member (bronchoscopist, nurse, or respiratory therapist). In addition, there are pre-COVID-19 data that suggest performing tracheostomy and gastrostomy procedures using a gastroscope and/or bronchoscope in the same sitting by a single specialty has a good safety profile with possible advantages of shorter ICU and hospital length of stay. ${ }^{82-85}$ This could be considered in institutions with such expertise, but there might be concerns for the additional time required to perform percutaneous endoscopic gastrostomy placement, leading to extended exposure time.

In summary, published data suggest an improvement in patient outcomes when using a multidisciplinary approach in percutaneous endoscopic gastrostomy. Therefore, we recommend that a multidisciplinary team be formed at each institution, to optimize expertise in the support and performance of tracheostomies to minimize risk and limit the size of the procedure team. Palliative care and infectious disease teams could offer meaningful insights into patients' overall goals of care, chance of meaningful recovery, and duration of viral shedding, factors that could affect the decision or the timing of tracheostomy. This multidisciplinary team paradigm is vital in the setting of a pandemic illness crisis when critical care needs exceed standard capacity resulting in surge level in which nonICU providers definitively benefit from an expert multidisciplinary team for collaborative decision-making in all aspects of tracheostomy care.

\section{Posttracheostomy Care of Patients With COVID-19}

\section{We suggest that patients be maintained with a} closed circuit while on mechanical ventilation with a tracheostomy tube and with in-line suction.

The inner cannula and tracheostomy tube changes and airway clearance are all considered to be AGPs. The optimal techniques for posttracheostomy care and timing of inner cannula and tracheostomy tube changes is not known in COVID-19, SARS, or Middle East Respiratory Syndrome. The best guidance comes from societal statements ${ }^{41,86,87}$ that balance an emphasis on 
safety both for patients and HCWs in the setting of viral pandemics $^{54,58,80,88}$ (Table 4).

The recommendations include use of enhanced PPE when performing tracheostomy care in patients with COVID-19 with the least number of HCWs present. If available, single-use disposable equipment should be used. Whenever possible, the patient should maintain a closed circuit at all times regardless of mechanical ventilation requirements. If the patient no longer requires mechanical ventilation but is not ready for capping trials, a closed circuit can be fashioned using a heat moisture exchanger with viral filter and in-line suction to minimize aerosol generation (Fig 2). Of note, heat moisture exchanger filters on patients with tracheal masks increase the resistance of the flow and may get clogged because of secretions. Inner cannulas should be changed on an as-needed basis rather than a scheduled routine. Tracheostomy tube changes can potentially be delayed until the patient tests negative for COVID-19, unless there is a clinical reason to proceed earlier. When using inhaled therapies, if the patient is on mechanical ventilation, an in-line nebulizer is preferred and if decannulated, a metered-dose inhaler with a spacer is recommended. Institutions have developed local guidance for when patients with COVID-19 can be cleared to move to a non-NP room (can be two negative nasopharyngeal swabs vs a negative nasopharyngeal swab and a negative tracheal aspirate). The timing of when to clear patients is unknown because most patients are asymptomatic when they first contract the virus. For decannulation, a rapid protocol is recommended to minimize aerosol generation. If the patient can tolerate their initial tracheostomy tube with the cuff deflated and either a speaking valve or a capping trial, then minimizing tracheostomy tube changes is advised. If a larger tracheostomy tube has been placed, HCWs could try to limit the number of tracheostomy tube changes and expedite a decannulation protocol as able.

These recommendations are designed to minimize risk for HCWs performing necessary AGPs on patients who have undergone placement of a tracheostomy tube. Some questions that are not addressed in the literature include how to provide appropriate nutrition and swallow evaluations for patients with tracheostomy and when airway clearance can begin for these patients. The disposition of posttracheostomy patients with COVID19 has not been addressed in the published literature. Typically, these patients are discharged to a long-term acute care facility; however, some long-term acute care facilities may not accept a patient with a tracheostomy tube prior to the first tracheostomy tube change and may require conversion to negative COVID-19 testing.

\section{Summary}

This consensus statement on tracheostomy is intended to offer guidance in the decision-making, preparation, timing, techniques, and postprocedural care of patients with COVID-19-related respiratory failure. We think we addressed the most common questions being faced by physicians during this pandemic pertinent to the practice of tracheostomy. One of the strengths of this expert panel report is that it represents the opinions and perspectives of intensive care and interventional pulmonary experts from 10 states with the highest burden of COVID-19 in the United States. The recommendations presented may change as more experience and data are collected during the COVID-19 pandemic. Because of the urgency of this situation, information needs to be made available to provide physicians general recommendations based on limited published data and panel's expertise. This statement should be considered a living document that could be updated in the future in a timely manner as new evidence becomes available.

\section{Acknowledgments}

Author contributions: All authors contributed to the design and analysis of the study and the writing of the manuscript.

Financial/nonfinancial disclosures: None declared.

\section{References}

1. China CDC Weekly. Vital surveillances: the epidemiological characteristics of an outbreak of 2019 novel coronavirus diseases (COVID-19) -China 2020. http://weekly.chinacdc.cn/en/article/id/ e53946e2-c6c4-41e9-9a9b-fea8db1a8f51. Accessed April 15, 2020.

2. Guan WJ, Ni ZY, Hu Y, et al. Clinical characteristics of coronavirus disease 2019 in China. N Engl J Med. 2020;382(18):1708-1720.

3. Huang Y, Chen S, Yang Z, et al. SARS-CoV-2 viral load in clinical samples of critically ill patients. Am J Respir Crit Care Med. 2020;201(11):1435-1438.

4. Wang D, Hu B, Hu C, et al. Clinical characteristics of 138 hospitalized patients with 2019 novel coronavirus-infected pneumonia in Wuhan, China. JAMA. 2020;323(11):1061-1069.

5. Grasselli G, Zangrillo A, Zanella A, et al. Baseline characteristics and outcomes of 1591 patients infected with SARS-CoV-2 admitted to ICUs of the Lombardy Region, Italy. JAMA. 2020;323(16):1574-1581.

6. Tay JK, Khoo ML, Loh WS. Surgical considerations for tracheostomy during the COVID-19 pandemic: lessons learned from the severe acute respiratory syndrome outbreak [published online ahead of print March 31, 2020]. JAMA Otolaryngol Head Neck Surg. https://doi.org/10.1001/jamaoto.2020.0764.

7. Angel LKZ, Chang SH, Rafeq S, et al. Novel percutaneous tracheostomy for critically ill patients with COVID-19 [published online ahead of print April 24, 2020]. Ann Thorac Surg. https://doi. org/10.1016/j.athoracsur.2020.04.010.

8. Michetti CPBC, Bulger EM, Davis KA, Spain DA. Performing tracheostomy during the Covid-19 pandemic: guidance and recommendations from the Critical Care and Acute Care Surgery 
Committees of the American Association for the Surgery of Trauma. Trauma Surg Acute Care Open. 2020;5(1):e000482.

9. Parker NP, Schiff BA, Fritz MA, Rapoport SK, Schild S, Altman KW, Merati AL, Kuhn MA. Tracheostomy recommendations during the COVID-19 pandemic 2020. https://www.entnet.org/content/ tracheotomy-recommendations-during-covid-19-pandemic. Accessed March 18, 2020.

10. Chen J, Qi T, Liu L, et al. Clinical progression of patients with COVID-19 in Shanghai, China. J Infect. 2020;80(5):e1-e6.

11. Huang C, Wang Y, Li X, et al. Clinical features of patients infected with 2019 novel coronavirus in Wuhan, China. Lancet. 2020;395(10223):497-506

12. Tran K, Cimon K, Severn M, Pessoa-Silva CL, Conly J. Aerosol generating procedures and risk of transmission of acute respiratory infections to healthcare workers: a systematic review. PLoS One. 2012;7(4):e35797.

13. CDC COVID-19 Response Team. Characteristics of health care personnel with COVID-19 - United States, February 12-April 9, 2020. MMWR Morb Mortal Wkly Rep. 2020;69(15):477-481.

14. statista. Total number of cases of coronavirus (COVID-19) in the United States as of April 21, 2020, by state. https://www.statista.com/ statistics/1102807/coronavirus-covid19-cases-number-usamericans-by-state/. Accessed April 21, 2020.

15. Rumbak MJ, Newton M, Truncale T, Schwartz SW, Adams JW, Hazard PB. A prospective, randomized, study comparing early percutaneous dilational tracheotomy to prolonged translaryngeal intubation (delayed tracheotomy) in critically ill medical patients. Crit Care Med. 2004;32(8):1689-1694.

16. Zheng Y, Sui F, Chen XK, et al. Early versus late percutaneous dilational tracheostomy in critically ill patients anticipated requiring prolonged mechanical ventilation. Chin Med J. 2012;125(11):19251930.

17. Andriolo BN, Andriolo RB, Saconato H, Atallah AN, Valente O. Early versus late tracheostomy for critically ill patients. Cochrane Database Syst Rev. 2015;1(1):CD007271.

18. Villwock JA, Jones K. Outcomes of early versus late tracheostomy: 2008-2010. Laryngoscope. 2014;124(8):1801-1806.

19. Young D, Harrison DA, Cuthbertson BH, Rowan K; TracMan Collaborators. Effect of early vs late tracheostomy placement on survival in patients receiving mechanical ventilation: the TracMan randomized trial. JAMA. 2013;309(20):2121-2129.

20. Mehta AB, Cooke CR, Wiener RS, Walkey AJ. Hospital variation in early tracheostomy in the United States: a population-based study. Crit Care Med. 2016;44(8):1506-1514.

21. Trouillet JL, Luyt CE, Guiguet M, et al. Early percutaneous tracheotomy versus prolonged intubation of mechanically ventilated patients after cardiac surgery: a randomized trial. Ann Intern Med. 2011;154(6):373-383.

22. Griffiths J, Barber VS, Morgan L, Young JD. Systematic review and meta-analysis of studies of the timing of tracheostomy in adult patients undergoing artificial ventilation. BMJ. 2005;330(7502):1243.

23. Terragni PP, Antonelli M, Fumagalli R, et al. Early vs late tracheotomy for prevention of pneumonia in mechanically ventilated adult ICU patients: a randomized controlled trial. JAMA. 2010;303(15):1483-1489.

24. Blot F, Similowski T, Trouillet JL, et al. Early tracheotomy versus prolonged endotracheal intubation in unselected severely ill ICU patients. Intensive Care Med. 2008;34(10):1779-1787.

25. Wang F, Wu Y, Bo L, et al. The timing of tracheotomy in critically il patients undergoing mechanical ventilation: a systematic review and meta-analysis of randomized controlled trials. Chest. 2011;140(6): $1456-1465$.

26. Gomes Silva BN, Andriolo RB, Saconato H, Atallah AN, Valente O. Early versus late tracheostomy for critically ill patients. Cochrane Database Syst Rev. 2012;(3):CD007271.

27. Szakmany T, Russell P, Wilkes AR, Hall JE. Effect of early tracheostomy on resource utilization and clinical outcomes in critically ill patients: meta-analysis of randomized controlled trials. Br J Anaesth. 2015;114(3):396-405.
28. Zhou F, Yu T, Du R, et al. Clinical course and risk factors for mortality of adult inpatients with COVID-19 in Wuhan, China: a retrospective cohort study. Lancet. 2020;395(10229):1054-1062.

29. Wang Y, Lu X, Chen H, et al. Clinical course and outcomes of 344 intensive care patients with COVID-19. Am J Respir Crit Care Med. 2020;201(11):1430-1434.

30. Bhatraju PK, Ghassemieh BJ, Nichols M, et al. Covid-19 in critically ill patients in the Seattle region - case series. $N$ Engl J Med. 2020;382(21):2012-2022.

31. Arentz M, Yim E, Klaff L, et al. Characteristics and outcomes of 21 critically ill patients with COVID-19 in Washington State. JAMA. 2020;323(16):1612-1614

32. Yang $\mathrm{X}, \mathrm{Yu} \mathrm{Y}, \mathrm{Xu}$ J, et al. Clinical course and outcomes of critically ill patients with SARS-CoV-2 pneumonia in Wuhan, China: a singlecentered, retrospective, observational study. Lancet Respir Med. 2020;8(5):475-481.

33. Delaney A, Bagshaw SM, Nalos M. Percutaneous dilatational tracheostomy versus surgical tracheostomy in critically ill patients: a systematic review and meta-analysis. Crit Care. 2006;10:R55.

34. Tien HC, Chughtai T, Jogeklar A, Cooper AB, Brenneman F. Elective and emergency surgery in patients with severe acute respiratory syndrome (SARS). Can J Surg. 2005;48(1):71-74.

35. Chee VW, Khoo ML, Lee SF, Lai YC, Chin NM. Infection control measures for operative procedures in severe acute respiratory syndrome-related patients. Anesthesiology. 2004;100(6):1394-1398.

36. Rajajee V, Fletcher JJ, Rochlen LR, Jacobs TL. Real-time ultrasoundguided percutaneous dilatational tracheostomy: a feasibility study. Crit Care. 2011;15(1):R67.

37. Saritas A, Kurnaz MM. Comparison of bronchoscopy-guided and real-time ultrasound-guided percutaneous dilatational tracheostomy: safety, complications, and effectiveness in critically ill patients. J Intensive Care Med. 2017: 885066617705641.

38. Gobatto AL, Besen BA, Tierno PF, et al. Comparison between ultrasound- and bronchoscopy-guided percutaneous dilational tracheostomy in critically ill patients: a retrospective cohort study. J Crit Care. 2015;30(1):220.e13-220.e17.

39. Gobatto ALN, Besen B, Cestari M, Pelosi P, Malbouisson LMS. Ultrasound-guided percutaneous dilational tracheostomy: a systematic review of randomized controlled trials and meta-analysis. J Intensive Care Med. 2020;35(5):445-452.

40. Simon M, Metschke M, Braune SA, Puschel K, Kluge S. Death after percutaneous dilatational tracheostomy: a systematic review and analysis of risk factors. Crit Care. 2013;17(5):R258.

41. Harrison L, Ramsden J. ENT UK Tracheostomy guidance during the COVID-19 Pandemic 2020; entuk.org/tracheostomy-guidanceduring-covid-19-pandemic. Accessed April 20, 2020.

42. Wei WI, Tuen HH, Ng RW, Lam LK. Safe tracheostomy for patients with severe acute respiratory syndrome. Laryngoscope. 2003;113(10): 1777-1779.

43. The First Affiliated Hospital, Zhejiang University School of Medicine. Handbook of COVID-19 Prevention and Treatment. 2020.

44. Meng L, Hua F, Bian Z. Coronavirus Disease 2019 (COVID-19) emerging and future challenges for dental and oral medicine. J Dent Res. 2020;99(5):481-487.

45. Wu Z, McGoogan JM. Characteristics of and important lessons from the coronavirus disease 2019 (COVID-19) outbreak in China: summary of a report of 72314 cases from the Chinese Center for Disease Control and Prevention [published online ahead of print February 24, 2020]. JAMA. https://doi.org/10.1001/jama.2020.2648.

46. Wang J, Zhou M, Liu F. Reasons for healthcare workers becoming infected with novel coronavirus disease 2019 (COVID-19) in China. J Hosp Infect. 2020.

47. Remuzzi A, Remuzzi G. COVID-19 and Italy: What next? Lancet. 2020;395(10231):1225-1228.

48. Chen WQ, Ling WH, Lu CY, et al. Which preventive measures might protect health care workers from SARS? BMC Public Health. 2009;9:81.

49. Moore D, Gamage B, Bryce E, Copes R, Yassi A; BC Interdisciplinary Respiratory Protection Study Group. Protecting health care workers 
from SARS and other respiratory pathogens: organizational and individual factors that affect adherence to infection control guidelines. Am J Infect Control. 2005;33(2):88-96.

50. Lie SA, Wong SW, Wong LT, Wong TGL, Chong SY. Practical considerations for performing regional anesthesia: lessons learned from the COVID-19 pandemic. Can J Anaesth. 2020;67(7):885-892.

51. Balakrishnan K, Schechtman S, Hogikyan ND, Teoh AYB, McGrath B, Brenner MJ. COVID-19 pandemic: what every otolaryngologist-head and neck surgeon needs to know for safe airway management. Otolaryngol Head Neck Surg. 2020;162(6):804808.

52. Ng K, Poon BH, Kiat Puar TH, et al. COVID-19 and the risk to health care workers: a case report. Ann Intern Med. 2020;172(11): 766-767.

53. Ran L, Chen X, Wang Y, Wu W, Zhang L, Tan X. Risk factors of healthcare workers with corona virus disease 2019: a retrospective cohort study in a designated Hospital of Wuhan in China [published online ahead of print March 17, 2020]. Clin Infect Dis., https://doi. org/10.1093/cid/ciaa287.

54. Givi B, Schiff BA, Chinn SB, et al. Safety recommendations for evaluation and surgery of the head and neck during the COVID-19 pandemic [published online ahead of print March 31, 2020]. JAMA Otolaryngol Head Neck Surg. https://doi.org/10.1001/jamaoto.2020. 0780 .

55. Ahmed N, Hare GM, Merkley J, Devlin R, Baker A. Open tracheostomy in a suspect severe acute respiratory syndrome (SARS) patient: brief technical communication. Can J Surg. 2005;48(1):68-71.

56. Foster P, Cheung T, Craft P, et al. Novel approach to reduce transmission of COVID-19 during tracheostomy. J Am Coll Surg. 2020;230(6):1102-1104.

57. Kwan A, Fok WG, Law KI, Lam SH. Tracheostomy in a patient with severe acute respiratory syndrome. Br J Anaesth. 2004;92(2):280-282.

58. Kowalski LP, Sanabria A, Ridge JA, et al. COVID-19 pandemic: effects and evidence-based recommendations for otolaryngology and head and neck surgery practice. Head Neck. 2020;42(6):1259-1267.

59. Centers for Disease Control and Prevention. Interim infection prevention and control recommendations for patients with suspected or confirmed coronavirus disease 2019 (COVID-19) in healthcare settings. https://www.cdc.gov/coronavirus/2019-ncov/ hcp/infection-control-recommendations.html. Accessed April 20, 2020 .

60. Pawar T, Pokharkar A, Gori J, et al. The technique and justification for minimally invasive surgery in COVID-19 pandemic: laparoscopic anterior resection for near obstructed rectal carcinoma. J Laparoendosc Adv Surg Tech A. 2020;30(5):485-487.

61. Cheng MP, Papenburg J, Desjardins M, et al. Diagnostic testing for severe acute respiratory syndrome-related coronavirus-2: a narrative review. Ann Intern Med. 2020;172(11):726-734.

62. Vargas M, Servillo G. Improving staff safety during tracheostomy in COVID-19 patients. Head Neck. 2020;42(6):1278-1279.

63. Wolfel R, Corman VM, Guggemos W, et al. Virological assessment of hospitalized patients with COVID-2019. Nature. 2020;581(7809): 465-469.

64. Zhou B, She J, Wang Y, Ma X. The duration of viral shedding of discharged patients with severe COVID-19 [published online ahead of print April 17, 2020]. Clin Infect Dis. https://doi.org/10.1093/cid/ ciaa451.

65. Liu WD, Chang SY, Wang JT, et al. Prolonged virus shedding even after seroconversion in a patient with COVID-19. J Infect. 2020;81(2):318-356.

66. Booth TF, Kournikakis B, Bastien N, et al. Detection of airborne severe acute respiratory syndrome (SARS) coronavirus and environmental contamination in SARS outbreak units. J Infect Dis. 2005;191(9):1472-1477.

67. Centers for Disease Control and Prevention. Discontinuation of transmission-based precautions and disposition of patients with COVID-19 in healthcare settings (interim guidance). 2020. https:// www.cdc.gov/coronavirus/2019-ncov/hcp/disposition-hospitalizedpatients.html. Accessed April 20, 2020.
68. European Centre for Disease Prevention and Control. Novel coronavirus (SARS-CoV-2) - discharge criteria for confirmed COVID-19 cases. 2020. https://www.ecdc.europa.eu/en/ publications-data/novel-coronavirus-sars-cov-2-discharge-criteriaconfirmed-covid-19-cases. Accessed April 202020.

69. Li Y, Yao L, Li J, et al. Stability issues of RT-PCR testing of SARS CoV-2 for hospitalized patients clinically diagnosed with COVID19. J Med Virol. 2020;92(7):903-908.

70. Ai T, Yang Z, Hou H, et al. Correlation of chest CT and RT-PCR testing in coronavirus disease 2019 (COVID-19) in China: a report of 1014 cases. Radiology. 2020:200642.

71. Wang W, Xu Y, Gao R, et al. Detection of SARS-CoV-2 in different types of clinical specimens. JAMA. 2020;323(18):1843-1844.

72. Yu F, Yan L, Wang N, et al. Quantitative detection and viral load analysis of SARS-CoV-2 in infected patients. Clin Infect Dis. 2020;71(15):793-798.

73. Bhatti N, Mirski M, Tatlipinar A, Koch WM, Goldenberg D. Reduction of complication rate in percutaneous dilation tracheostomies. Laryngoscope. 2007;117(1):172-175.

74. Mirski MA, Pandian V, Bhatti N, et al. Safety, efficiency, and costeffectiveness of a multidisciplinary percutaneous tracheostomy program. Crit Care Med. 2012;40(6):1827-1834.

75. Norwood MG, Spiers P, Bailiss J, Sayers RD. Evaluation of the role of a specialist tracheostomy service. From critical care to outreach and beyond. Postgrad Med J. 2004;80(946):478-480.

76. Frank U, Mader M, Sticher H. Dysphagic patients with tracheotomies: a multidisciplinary approach to treatment and decannulation management. Dysphagia. 2007;22(1):20-29.

77. Arora A, Hettige R, Ifeacho S, Narula A. Driving standards in tracheostomy care: a preliminary communication of the St Mary's ENT-led multi disciplinary team approach. Clin Otolaryngol. 2008;33(6):596-599.

78. Cetto R, Arora A, Hettige R, et al. Improving tracheostomy care: a prospective study of the multidisciplinary approach. Clin Otolaryngol. 2011;36(5):482-488.

79. Chao TN, Braslow BM, Martin ND, et al. Tracheotomy in ventilated patients with COVID-19. Ann Surg. 2020;272(1):e30-e32.

80. Pichi B, Mazzola F, Bonsembiante A, et al. CORONA-steps for tracheotomy in COVID-19 patients: a staff-safe method for airway management. Oral Oncol. 2020;105:104682.

81. Wax RS, Christian MD. Practical recommendations for critical care and anesthesiology teams caring for novel coronavirus (2019-nCoV) patients. Can J Anaesth. 2020;67(5):568-576.

82. Yarmus L, Gilbert C, Lechtzin N, Imad M, Ernst A, FellerKopman D. Safety and feasibility of interventional pulmonologists performing bedside percutaneous endoscopic gastrostomy tube placement. Chest. 2013;144(2):436-440.

83. Folch E, Kheir F, Mahajan A, et al. Bronchoscope-guided percutaneous endoscopic gastrostomy tube placement by interventional pulmonologists: a feasibility and safety study. J Intensive Care Med. 2018:885066618800275.

84. Nobleza COS, Pandian V, Jasti R, Wu DH, Mirski MA, Geocadin RG. Outcomes of tracheostomy with concomitant and delayed percutaneous endoscopic gastrostomy in the neuroscience critical care unit. J Intensive Care Med. 2019;34(10):835-843.

85. Belanger A, Akulian J. Interventional pulmonology in the intensive care unit: percutaneous tracheostomy and gastrostomy. Semin Respir Crit Care Med. 2014;35(6):744-750.

86. Heyd CP, Desiato VM, Nguyen SA, et al. Tracheostomy protocols during COVID-19 pandemic. Head Neck. 2020.

87. Engels PT, Weitzel E, Witterick IJ, et al. Recommendations from the CSO-HNS Taskforce on performance of tracheotomy during the COVID-19 pandemic. https://www.entcanada.org/wp-content/ uploads/COVID-19-Guidelines-CSOHNS-Task-Force-Mar-232020.pdf. Accessed March 18, 2020.

88. Expert consensus on preventing nosocomial transmission during respiratory care for critically ill patients infected by 2019 novel coronavirus pneumonia [in Chinese]. Zhonghua Jie He He Hu Xi Za Zhi. 2020;43(4):288-296. 